\title{
Food on the table: The role of livelihood strategies in maintaining nutritional status among ART patients in Kenya and Zambia
}

\author{
Fiona Samuels \\ Naomi Rutenberg \\ Population Council \\ Joseph Simbaya \\ Jerry Okal \\ Population Council \\ Nicodemus Kisengese
}

See next page for additional authors

Follow this and additional works at: https://knowledgecommons.popcouncil.org/departments_sbsr-hiv

Part of the Demography, Population, and Ecology Commons, Family, Life Course, and Society Commons, Gender and Sexuality Commons, International Public Health Commons, and the Medicine and Health Commons How does access to this work benefit you? Let us know!

\section{Recommended Citation}

Samuels, Fiona, Naomi Rutenberg, Joseph Simbaya, Jerry Okal, Nicodemus Kisengese, Stanley Luchters, Susan Kaai, and Scott Geibel. 2008. "Food on the table: The role of livelihood strategies in maintaining nutritional status among ART patients in Kenya and Zambia," Horizons Research Summary. Washington, DC: Population Council. 


\section{Authors}

Fiona Samuels, Naomi Rutenberg, Joseph Simbaya, Jerry Okal, Nicodemus Kisengese, Stanley Luchters, Susan Kaai, and Scott Geibel 


\section{Food on the Table: The Role of Livelihood Strategies IN Maintaining Nutritional Status Among ART Patients in Kenya and Zambia}

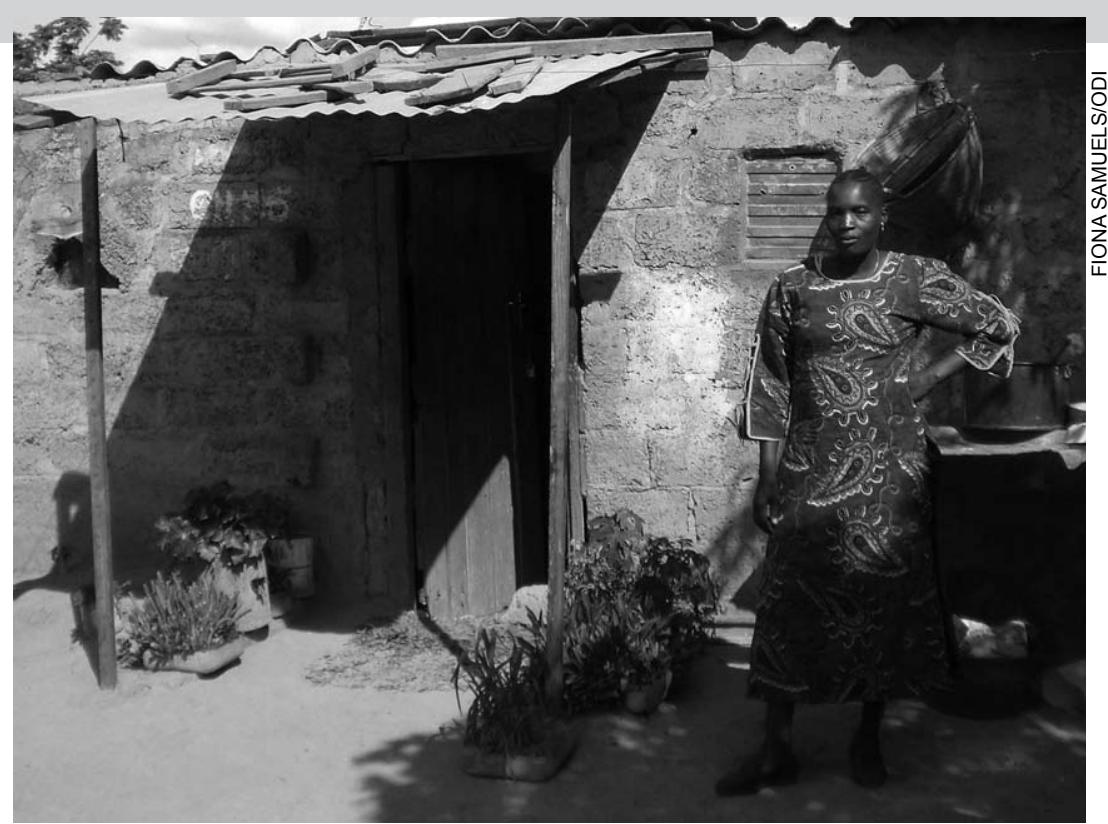

Conditions of life for a woman living with HIV and on ART in Lusaka, Zambia

livelihoods evolve and adapt to deal with the multifaceted nature of HIV.

HIV has implications for food and nutrition security, and in eastern and southern Africa, evidence pointing to a vicious cycle between HIV and food and nutrition insecurity is mounting. ${ }^{2}$ Programs are now being implemented that link HIV to food and nutritional security, as well as to livelihoods. However, additional evidence on the effectiveness of these interventions, particularly as they relate to antiretroviral therapy (ART), is needed to inform policy and program efforts to improve treatment and to strengthen resilience to the impacts of HIV. Additionally, further insights are needed on how to move beyond the concept of therapeutic supple- mentary feeding to encapsulate broader notions of food security.

To build this evidence base, the Horizons Program, with the Overseas Development Institute and the International Centre for Reproductive Health, conducted a study to explore and understand the role that livelihood strategies play, in particular the ability of ART patients to achieve food security or adequate access to food. In addition to presenting findings from the study that explored the livelihood strategies of people on ART, this summary also presents recommendations on how to transition people on ART from therapeutic and supplementary feeding to sustainable, long-term livelihood security.

To read more about this study, go to www.popcouncil.org/horizons/projects/KenyaZambia_FoodART.htm
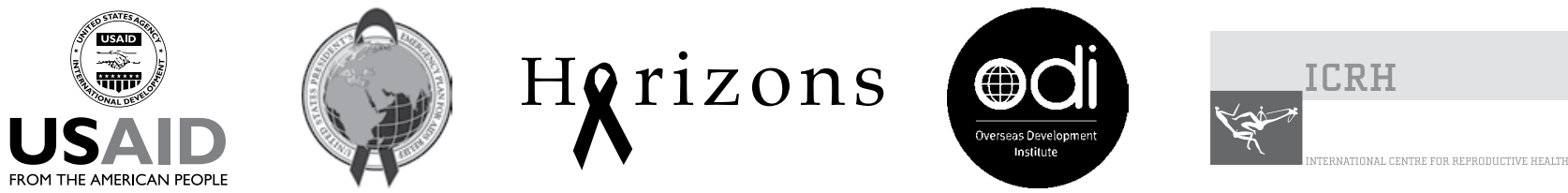


\section{Study Settings}

The study was carried out in Mombasa, Kenya and in Lusaka, Zambia.

National HIV prevalence in Kenya has declined from 14 percent in the mid 1990s to 5 percent in 2006 (UNAIDS 2007). In the 15-49 year old age group, HIV prevalence in women is almost twice that of men (9 percent compared to 5 percent). Urban residents have a significantly higher risk of HIV infection (10 percent) when compared to rural residents (6 percent). Similarly, prevalence in urban women is 12 percent compared with less than 8 percent for rural women. As of December 2007, a total of 177,000 people were receiving ART, representing an estimated coverage of 38 percent of those who need it (WHO 2008).

The coastal town of Mombasa is the second largest city in Kenya, with a population of one million. Located in the southeastern part of Kenya, it plays an important role in the country's economy, not only for its imports and exports through its port-which is the largest in East Africa-but also as a destination for tourists visiting Kenya. HIV prevalence in the 15-49 year old age group is 6 percent in the Coast province, of which Mombasa is the capital (NASCOP 2005).

Zambia, with a population of just fewer than 12 million people, is classified by the World Bank as a severely indebted low-income country. Almost three-quarters of the population lives below the poverty line, with 58 percent characterized as extremely poor, and nearly 70 percent of the population has difficulty accessing basic social services needed to improve their well-being. Poverty and hunger are widespread; exacerbated by cyclical droughts and the devastating impact of HIV (UNDP 2003).

AIDS continues to be one of the biggest causes of death in Zambia. According to the Demographic and Health Survey (2001-2002), 15.6 percent of the adult population is HIV-positive. Lusaka, the capital city and the location for this study, has a prevalence rate of 22 percent for 15-49 year olds. Out of an estimated one million HIV-positive Zambians, 370,000 are in urgent need of ART. As of December 2007, a total of 151,999 people were reported to be on ART, representing 46 percent coverage of those who need it (WHO 2008). As of August 2005, treatment and laboratory costs at public institutions became free, though patients must still pay registration fees and other associated costs.

\section{Methodology}

A formative assessment was carried out using cross-sectional data. Quantitative and qualitative (in-depth interviews [IDIs] and focus group discussions) data collection methods were used. The study was nested in two existing Horizons operations research projects in Zambia and Kenya exploring issues around ART and adherence. In Kenya, data from an already existing quantitative survey with people on ART was used ( $\mathrm{n}=118)$; in Zambia, additional questions on issues relating to livelihoods and food security were added to a questionnaire for people on ART $(\mathrm{n}=375)$.

In both countries, a sub-sample of 16 respondents was chosen for the IDIs: a total of 32 people on ART across the two countries were interviewed. In order to select the qualitative sample of people on ART, sociodemographic, adherence, and body mass index (BMI) data from quantitative studies among people on ART in Kenya and Zambia were analyzed. Study respondents were grouped into four categories according to adherence and nutritional status, in which someone with a BMI of $>18$ was considered to have good nutritional status:

- Adequate (BMI > 18) nutritional status and good adherence (> 95\%) (As).

- Adequate $(\mathrm{BMI}>18)$ nutritional status and poor adherence $(<95 \%)$ (Bs).

- Inadequate $(\mathrm{BMI} \leq 18)$ nutritional status and good adherence (> 95\%) (Cs).

- Inadequate $(\mathrm{BMI} \leq 18)$ nutritional status and poor adherence $(<95 \%)(\mathrm{Ds})$.

IDIs were then conducted with samples of respondents from each of the four groups (four IDIs were carried out for each category).

An innovative aspect of the study is that in addition to carrying out IDIs with people on ART, members of their family, cluster members (CMs), or members of their livelihood networks were interviewed. Cluster members are defined as "a group of producers and consumers between which there are multiple resource ex- 
changes, usually based on the factors of kinship, labour and food exchange, and or common access to draught power" (Samuels et al. 2006). Each person on ART was asked to identify at least two people in their cluster or livelihood network; a total of 32 cluster members were interviewed in each country.

Existing frameworks, scales, and tools for measuring food security were used in both the quantitative and qualitative instruments. One method for analyzing the data used a positive deviance (PD) approach, referring to a situation in which some individuals employ potentially uncommon and beneficial practices that allow them to have better health outcomes compared to their peers or others in their community. In this case, an individual who manages to achieve food and livelihood security resulting in a high BMI as well as high levels of adherence could be said to be engaged in PD behaviors.

Data were collected between September and December 2006 in Kenya and September 2006 to January 2007 in Zambia. A limitation of the study is the relatively small sample size for the qualitative study, especially since the IDIs were divided by the cells according to BMI and adherence (see above).

\section{Description of the Samples}

In Kenya, out of a total of 118 respondents, around two-thirds were women, the median age was 36 , and respondents had a median BMI of 20.8. In terms of the correlation between BMI and adherence, the majority had a BMI of 18 or over and the majority reported adhering at least 95 percent of the time (73 percent), with only 5 percent reporting a BMI of less than 18 and not reporting a 95 percent adherence rate (see Table 1).

Among the 16 people interviewed in Kenya (4 in each of the cells) for the qualitative component, the majority (10) were women; their ages ranged from 29 to 57 , with a median of 35 . Six of the respondents were married or cohabiting, with a further six reporting being single; only one had been widowed. The length of time people had been on ART ranged from one to six years. The majority of respondents (11) stated that they had been on ART for two or three years.

A total of $32 \mathrm{CMs}$ were interviewed, the majority (20) of which were women. Most CMs and people on
ART lived within the four administrative divisions of Mombasa district. CMs who lived far away were usually relatives and were often called upon for help with "big problems;" nearby CMs usually supported the day-to-day difficulties. The median age of CMs was 36.5 , with a range of 25 to 75 . The majority were married or cohabiting ( 72 percent); in terms of education, only 3 had never attended school, with the rest being split between having completed primary (10), secondary (11), and tertiary (8) education. Only five reported being unemployed, the rest were more or less equally split between being employed and being self-employed. Half of the CMs (16) were related to people living with HIV - the majority were mothers, followed by sisters and brothers; eight were friends, four were spouses, and four were in the "other" category, including a pastor and a boyfriend.

CMs usually provided support to the participants with general needs. The most common form of support was providing money and doing household chores. In return, a few people on ART exchange money and gifts with the CM. The majority of CMs (26/32) knew the person's HIV status; this knowledge usually enhanced and cemented the relationship between the CM and the person on ART. In some cases a few CMs sought to know their own status after knowing that of the person on ART. Some CMs mentioned facing difficulties, when, for instance, there were insufficient resources (food, money, time). Despite having had to share the little resources they had, some CMs mentioned that they derived a sense of satisfaction from helping and eventually seeing an improved health status of their friends or relatives.

Table 1 BMI by adherence in Kenya

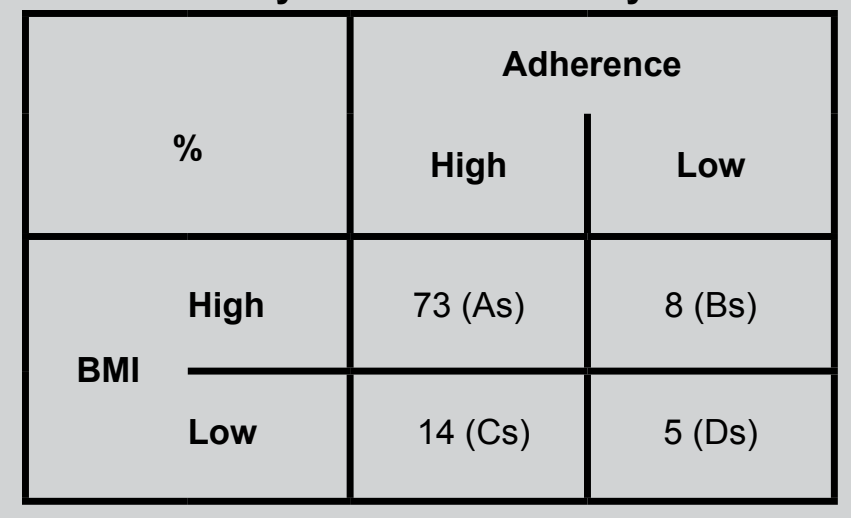


In Zambia, a total of 375 respondents were interviewed in two low-income, high-density residential areas in Lusaka: Ngombe and Bauleni. One-third of the sample were women, with an overall median age of around 37. The majority of people in both sites were married and had completed a primary school education, with a significant number from Bauleni also having completed secondary level education. The majority of respondents had known their HIV status for more than 12 months, and a majority had been on ART for at least six months. As in Kenya, the majority of respondents had a BMI of 18 or more and reported being adherent 95 percent of the time (79 percent) (see Table 2 ).

A total of 19 IDIs (including three pilot ones) were carried out with people on ART (four in each of the cells and three additional ones). The majority of respondents were women (15); the mean age of respondents was 37 in Ngombe and significantly younger in Bauleni, 28. Eight people in the sample were married and six were widowed; 10 reported having never attended school. The time that people had been on ART ranged from six months to three years, with 10 people having been on ART for two years or more.

Eighteen CMs were interviewed in Ngombe and 16 in Bauleni. The majority of CMs were women (28). Ages of CMs in Ngombe ranged from 20-62, with a mean of 39; in Bauleni the range was from 25-78, with a mean of 44 . Most CMs were friends (17) and family (16) of the people on ART-family included six sisters, five parents, two spouses, two children, and one brother. The majority of CMs lived within the same residential area or compound and within a 20 minute walk of the person on ART; some mentioned relatives

Table 2 BMI by adherence in Zambia

\begin{tabular}{|c|c|c|c|}
\hline \multicolumn{2}{|c|}{$\%$} & \multicolumn{2}{|c|}{ Adherence } \\
\hline \multirow{2}{*}{ BMI } & High & 79 (As) & 10 (Bs) \\
\hline & Low & 9 (Cs) & 2 (Ds) \\
\hline
\end{tabular}

living within Lusaka but in other compounds. Some CMs were also on ART and some people living with HIV and CMs met at clinics. Quite a few CMs knew people living with HIV for approximately the period of treatment or since they became ill. Most knew the person's HIV status-for some it was the main reason for supporting them and strengthened their relationship.

The most frequently mentioned support method was food provision followed by giving money and then a range of other support including collecting food, cooking, bathing, and providing emotional support. Although the majority of CMs said they had no problems supporting people on ART, some talked about having scarce resources (e.g., food or money), which raises concerns about the sustainability of their support.

\section{Key Findings}

\section{The majority of people on ART in Zambia are food insecure and most people on ART in both Zambia and Kenya frequently miss meals.}

Half of the people (50 percent) in the quantitative survey in Zambia reported having two meals per day. In the qualitative study ${ }^{3}$ in Kenya all but one respondent reported having three meals per day. When applying a pre-validated food insecurity measure (FANTA 2007) to the quantitative data in Zambia, only 6 percent of respondents were food secure, 24 percent somewhat food secure, 34 percent somewhat food insecure, and 36 percent food insecure. Similarly, while the majority of respondents in the IDIs reported eating three meals per day (though some said they had two meals but made sure their children/grandchildren had three), the majority in both Zambia (15/16) and Kenya (11/16) also reported skipping meals if food and/or money was not available. Missing meals was often based on seasons, with people reporting missing more meals during the rainy season. Missing meals was also linked to lack of available piecework opportunities to earn cash.

What causes [missing of meals] is that sometimes you can have mealie meal but no relish or charcoal or money to buy these things. So you sleep without eating anything until the next day when you go to look for money on credit, you buy charcoal, you cook and eat.

Man, Lusaka 
In terms of diet there was much more variety in Kenya, with people reporting eating a large range of food items. In Zambia, the majority of people reported eating nshima (the Zambian staple of porridge made from maize meal) and a vegetable relish (accompaniment to the nshima) the previous day.

Snacking played an important role in people's dietary intake, and is particularly prevalent in Kenya, with many people snacking around three times per day on a large variety of food items. In Zambia there was less variety of snacks, with people snacking most on seasonal foods. Ability to snack was also related to availability of cash.

\section{Most food is purchased.}

The majority of respondents in both Zambia and Kenya, from both the quantitative and qualitative studies, reported purchasing food from the market or obtaining food items on credit from shops/stalls.

The quantitative study in Kenya showed that people spend the most money on meat and dairy products, followed by cereals and vegetables. In Zambia, the quantitative survey found that people spend between Ks5000 and Ks10,000 4 per day.

Since the majority of respondents were buying food, their challenges included the need to find income with which to purchase food, price fluctuations, and high prices in general.

\section{You know when you feel like eating something you must have money. If the money is not enough you just have to buy what you can afford. That is why we mostly eat ugali [maize poridge] and mboga [vegetables].}

\section{Woman, Kenya}

In order to purchase food, people need to engage in some form of livelihood activity in order to earn cash. Additionally, people can draw down on assets or they can resort to loans and credit schemes. In both Zambia and Kenya, 34 percent of respondents in the quantitative survey indicated that they engage in self-employment/business in order to make a living. In the qualitative study in Kenya, 14 respondents reported having

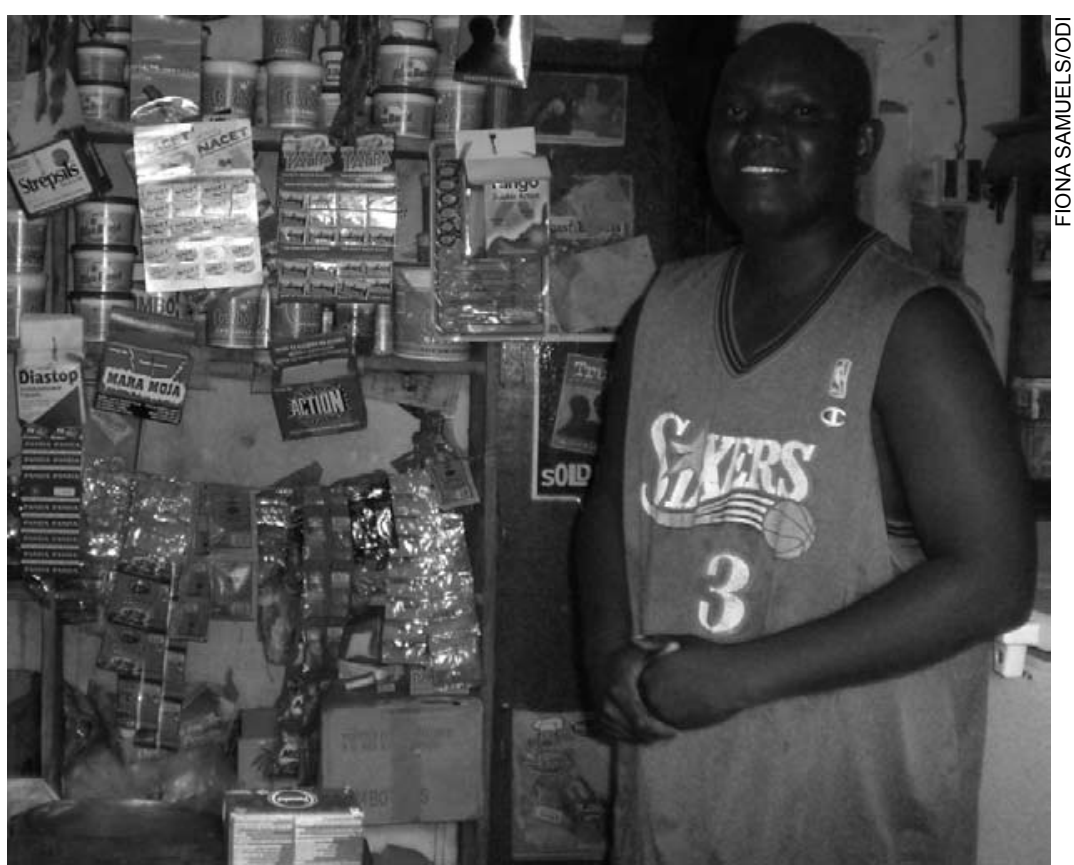

A shopkeeper in Kenya and a member of a livelihood network of a person on ART

jobs with salaries ranging from Ks1,500 to Ks25,000 per month. In Zambia, in contrast to Kenya, most respondents in the IDIs made a living from piecework.

Piecework can vary and can be conceptualized as a continuum ranging from highly insecure and unsustainable to more secure, ending up eventually in permanent, often formal sector, employment. Piecework can also be gendered, at one extreme one finds women washing and mending clothes, knitting and drawing water, for instance, moving along the continuum to buying and selling vegetables and charcoal to being a hairdresser. The livelihoods of the three male respondents in Zambia did not lie at one extreme, but rather somewhere in the middle in terms of permanence and security (one mended batteries, one was a cobbler, and the third was an office clerk, occupations that also require different skills sets).

Some respondents indicated that they earn additional money by renting out rooms. This, in fact, can become a major component of a person's livelihood since it represents a continuous source of income and is often used as a capital outlay for starting a business. Three respondents in Zambia mentioned renting out rooms, one woman in Bauleni had two rooms she rented out, a man in Ngombe rented out five rooms and another woman from Ngombe had one tenant. Respondents reported that the income raised from renting is fed 
back into businesses and generally used to buy food. Both women who reported renting out rooms have farms; the man used to have a relatively large farm until the land was reclaimed for housing. Additionally, tenants were sometimes a source of food and support, with relationships between the tenant and owner often being one of give and take.

In Kenya the quantitative survey found that 20 percent of households at baseline had received a loan, which went up to 28 percent at 12 months. The source of loans was equally split between borrowing from individuals/relatives, getting a salary advance, obtaining credit from a bank or a "merry-go-round," an informal group credit and savings scheme. In Zambia, while a few respondents in the qualitative component were members of informal groups, none had ever received any loans from formal schemes. While they all knew about their existence, the majority feared getting a loan, essentially because of the strict repayment schedules, as this woman from Bauleni reports: "I fear, if I fail to pay, I can make my children suffer."

\section{Most food supplementation is shared among family members and others.}

The majority of respondents in Zambia (70 percent from the quantitative survey and 94 percent of the

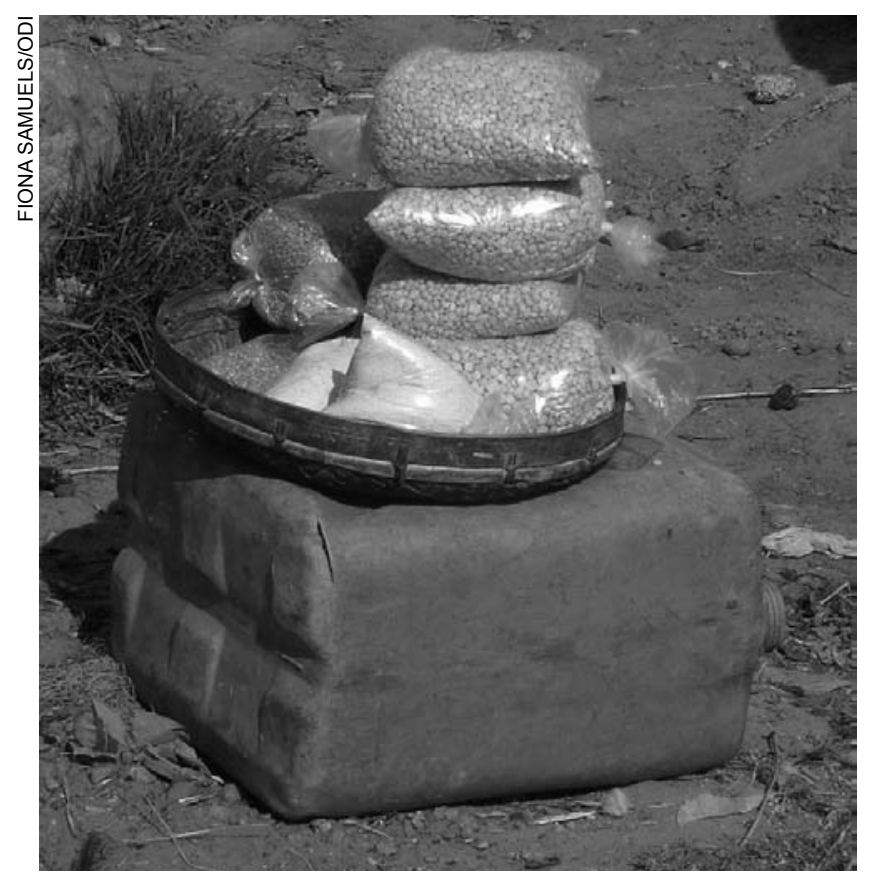

Food supplementation being sold in Zambia.
IDIs) had received food supplementation-eight respondents from the qualitative survey continued to received it at the time of the interview and out of these, two said that it was their most important source of food. In Kenya, while the majority of respondents in the qualitative study had heard about food supplementation programs, only two had received any. Some were unsure if they were eligible, others mentioned that those that received food were members of particular groups (e.g., at the church or hospital) or that it was given to widows or orphans.

Respondents who received food supplementation usually got it on a monthly basis and from home-based care programs. The food people received included wheat, soya beans, beans, peas, cooking oil, maize, eggs, and kapenta. All respondents shared the food supplementation with their families; some also shared with neighbors, friends, and others in their livelihood network. Some spoke about selling it in order to buy other food items.

Yes, we share with people in this house and my neighbors when they ask for it, and I give them to give to their children because they assist me with their wheelbarrow, so I give them every time.

\section{Woman, Lusaka}

Challenges with food supplementation included unpredictability and infrequency of supply as well as discrepancies between the amounts that patients received. Administrative and access issues were also raised by respondents: some noted the corrupt and unprofessional behavior of those in charge of handing out food; others spoke about the length of time between registering and receiving food. Stigma was also faced by some when waiting in line to receive food supplementation. The quality of the food was also questioned, with people saying it caused health problems and reporting difficulties in preparing and adjusting to the foods.

It's [wheat] okay, but at first wheat gave me problems because it's for the first time. I had stomach pains and I was failing to go to the toilet... Someone explained that I need to cook it very much, after that you add milk or butter.

Woman, Lusaka 


\section{For those who receive food supplementation, it represents a lifeline enabling them to eat and develop social capital.}

The majority of respondents expressed great relief when being given food supplementation.

... without these foods, we could have died of hunger especially our situation where my husband does not work. Where can I, a woman, go and find food?

$$
\text { Woman, Ngombe }
$$

Usually there is a give-and-take approach, where people will share the little they receive, on the unspoken understanding that they will also receive when they are in need. As such, food supplementation, and giving and taking of food in general, can be seen as a crucial way of generating and building social capital.

If things become difficult, we ask from our neighbors...I remember asking for salt last month...yesterday [in return] I gave my neighbor some tomatoes.

Woman, Bauleni

\section{Livelibood networks are key in times of diff- culty and consist of a range of people including family members, friends, and shopkeepers.}

When facing difficulty, usually in relation to lack of food or money to buy food, people resort to a variety of strategies, including turning to their network of relatives and friends, getting items on credit from shopkeepers, borrowing money, budgeting their own money better, selling assets, praying, begging, and, in Kenya, turning to merry-go-rounds, and getting a loan. In Zambia, people also spoke about using less charcoal and resorting to firewood, eating vegetables from the garden, and staying without food. While many in Zambia did mention selling assets, it appears this was something they did more in the past than currently.

In the qualitative study in Kenya, family members, including mother/parents, siblings, spouses, and other in-laws, were identified as the most important members of livelihood networks and listed most often; other members of livelihood networks included friends, workmates, shopkeepers, pastors/church members (for advice/company), and neighbors. In Zambia, while family and relatives were a key source of support, neighbors in particular were repeatedly mentioned as playing an important role in the survival of households and individuals: 12 people said they asked their neighbors for assistance when in need.

\section{Neighbors are important members of an indi- vidual's livelihood network, as often what is most significant to daily survival is proximity and immediacy.}

As was noticed particularly in Zambia, for day-to-day survival people were often heavily dependent on others living close to them, and in particular their neighbors. Though relatives were clearly important in the livelihood networks, because often they were living at a distance (in other towns in Kenya, in the same town in Zambia but far away), they were only turned to when needs were large (e.g., when someone wanted a large outlay of money, when the effects of the illness were becoming overwhelming, or when perhaps they were requesting to come and stay with them). Daily survival was much more about proximity.

Thus people turned to neighbors for a range of assistance including food, feeding their children, general assistance, and taking them to the clinic.

When asked [for food] I give because I realize that one day I would be in a similar situation and I would run to my neighbor.

Woman, Lusaka

...sometimes neighbors help by calling the young ones for a meal when we have not prepared in time.

Woman, Lusaka

Tenants are not only useful as a source of income, but can become a source of support and food. One woman from Lusaka described how she developed a close relationship with her tenant and shared food with her: the tenant sometimes sold fruit and gave her some; she has a small garden in front of her house where she grows pumpkin leaves and maize and she shares the garden with her tenant. 
Respondents also reported turning to members of support groups and home-based care teams for support, which was also related to proximity.

\section{Study participants report a diverse use of gardens/small farms for support.}

In Kenya only 5 percent of respondents from the quantitative study reported having a farm. Six (out of 16) respondents from the qualitative study reported engaging in farming activities; two saw it as their main source of livelihood and four said they farmed in addition to their "main" jobs as teachers or managers of kiosks. Farms are mostly family owned plots, measure between one and six acres in size, are located outside the city, and are farmed for subsistence purposes.

Twelve percent of respondents in the quantitative study in Zambia mentioned having a farm, with considerably more in Bauleni than in Ngombe (23 percent versus 5 percent). Nine respondents in the qualitative study reported having a garden or field from which they sourced their household food; out of these nine people, two mentioned farming as their main livelihood. Crops grown in these gardens included maize, beans, pumpkins, and sweet potato leaves. Produce from these gardens and fields was kept for household consumption, with the excess sometimes sold.

Among those less well-off nutritionally who had a garden or small farm, the produce represented a key food source; small amounts of vegetables were sold in order to raise money to buy other food items, and these gardens/farms were crucial in the exchange relationships which form part of a livelihood network. Among those who were better off nutritionally, farms were not key to survival; the produce was shared between many relatives and sold if there was a surplus.

I grow [in her small garden] Cibwabwa [pumpkin leaves] and maize to avoid begging or buying, green leaves to avoid buying...

Woman, Lusaka

We do have a small garden outside, we grow maize and vegetables, it is only 3 meters wide and 3 meters in length... We grow maize for consumption only when they are ready, we get 5 [cobs] per day and they can last for a month, that is when they get finished. We grow pumpkin leaves and sometimes we harvest some pumpkins or 5 of them.

Woman, Lusaka

\section{With ART, respondents' health has rebounded but their liveliboods lag behind.}

Most of the respondents, both men and women, had in the past, or before they became sick, more secure livelihoods and many have moved down the livelihood continuum. Some of these moves can be explained by the life cycle, since as people get older they often become less productive and hand over responsibility to the younger generation. But for many, this was not the case, and they moved down it as a result of sickness. For some, what they did in the past did influence their present occupations, but often they were at a lower level than before they became sick.

The effect of the illness was, therefore, seen through loss of jobs, sale of assets, collapse of traditional safety nets, and generally lower standards of living and reduced quality of life. As a result of ART, however, the majority felt like they had returned to their previous health status, but livelihood opportunities were not available for them, therefore making it difficult to recover their previous standards of living. For those who appeared to have done so, it was usually as a result of having some injection of capital.

The standard I was living in before getting HIV was a bit higher as I had a husband who was rich. I have not yet attained that... [later on she explains how she resorted to selling some of her assets]... I sold my radio when I was sick, and before I started medication.

Woman, Kenya

Before I got tested I used to stay with my parents and after being tested...I was sick I was still staying with my parents, but I started gaining [weight], when I started taking my medication and then things started opening up, I started working and my life started being a different one. So I shifted from home, I started staying in my own place, then, I moved on with my life.

Woman, Kenya 


\section{Respondents with high adberence and high BMI tended to be more self-reli- ant and more likely to have multiple income sources.}

Those with high adherence and high BMI tended to have a greater number of assets (e.g., farms, rooms to rent), were more connected to the formal sector, and had someone to fall back on in times of need.

Respondents with low adherence and low BMI had more tenuous livelihoods, were less likely to have farms and gardens, and were more likely to rely on piecework.

When analyzing some key variables affecting livelihood security and following the PD approach, by focusing on the best, the As (whose adherence is > 95\% and BMI > 18 ) and the worse, the Ds (whose adherence is $<95 \%$ and $\mathrm{BMI}<18$ ), case scenarios, the following findings emerged. It should be reiterated that these findings should be treated with caution because of the small samples sizes in the qualitative study in each of the cells (in particular, in the $\mathrm{D}$ category in the quantitative study, see Tables 1 and 2).

\section{Kenya}

Marital status and household size: Respondents in group A tended to be single and live in smaller households, while those in group $\mathrm{D}$ were married and lived in larger households.

Education: Respondents in group A were more educated than those in group D, with all having had some form of education (two group A respondents reached secondary level, while only two group D respondents even reached primary level).

Employment: Respondents in group A tended to be more involved in formal/permanent employment and therefore had higher earning capacities than those in group D.
Coping: Respondents in group A were much more selfreliant than those in group $\mathrm{D}$, of whom all except one were dependent on others.

Savings and credit: Two people in group A had savings accounts; none had a savings account in group $\mathrm{D}$, though one was a member of a merry-go-round.

Food consumption: Respondents in group A had access to sufficient, diverse, and often relatively expensive food, eating at least three meals a day and often snacking in between. For respondents in group D, skipping meals was more common and the variety of food was more limited, with less expensive foods being consumed when compared to group A.

\section{Zambia}

Marital status and housebold size: No difference between As and Ds.

Education: No difference between As and Ds.

Employment. Respondents in group A tended to have more permanent ways of earning an income, arguably requiring more skills, and they also had assets with which they could earn money, including rooms to rent 
out and farms where produce was used both for consumption and sale. In group $\mathrm{D}$, piecework was key to their earnings, though one person did report having a more permanent job as a hairdresser.

Coping. Respondents in group A were able to be selfreliant, though they often had one key person who they relied on; in group D, respondents had a variety of coping strategies, including borrowing from various people.

Savings and credit. None had savings accounts or were members of schemes.

Food consumption: While respondents in group A did buy food items, their farms played an important role in their food security strategies; in group D none had farms and they relied on purchasing food or receiving it from others.

\section{Recommendations}

Given that food supplementation is not a long-term solution, findings from this study highlight the importance of livelihood strategies in helping people on ART adhere to medication regimens and achieve good nutrition. The study has identified four different areas in which inputs and support could be provided in order to bolster livelihood strategies. These areas are: skills, livelihood networks, assets, and food and cash transfer projects. These four areas are not mutually exclusive and as such are overlapping and inter-linked.

\section{Focus on building skills and buman capacity.}

Respondents both in Zambia and Kenya who appeared to be most secure in terms of their livelihoods and who are in the best case scenarios (the As) are those involved in more secure employment, often in the formal sector and often requiring skills and learning. Education and the provision of skills can take many forms and are just as important, if not more so, for people on ART, who may need to rebuild confidence, regain their skills, and build new skills. Health services must establish linkages with wrap-around programs that increase skills and opportunities for earning income and building assets, which contribute to food security and good nutrition.

\section{Build on existing livelihood networks.}

The study shows that day-to-day relationships with neighbors and others who live in close proximity are crucial to an individual's survival. These mutual support relationships consist essentially of sharing of food but also sometimes of sharing of tasks such as taking an individual to the clinic and looking after children. Through such livelihood networks an individual's social capital is built and maintained. Ways of building on these informal support structures and how to, for instance, transform them into more systematic livelihood mechanisms, needs to be further explored.

\section{Support the development of an asset base among people on $A R T$}

Not surprisingly, the study showed that people with some form of asset base have more secure livelihoods and are better able to adhere. With people on ART now being well enough to return to earning a living, opportunities are lacking. One means of promoting opportunities is through supporting the development of an asset base. Broadly speaking, three asset domains can be identified:

\section{Property}

The study found that those who had a room to rent, which brought in a regular income, were more secure. Ways of enabling people to acquire property need to be explored, perhaps through microcredit (see below), some kind of targeted construction loans, and/or some cooperative or partnership agreements.

\section{Land and urban farming and gardening}

The study also found that people with land were more secure, were better able to maintain a balanced diet, and had their land as an important asset to fall back on in difficult times. Urban gardening and farming should, therefore, be encouraged among people on ART. Ways of encouraging people to acquire land, perhaps cooperatively, need to be explored; additionally, how to support growing crops through subsidized inputs, both for cash and subsistence purposes, needs to be explored. 


\section{Savings}

Different forms of microcredit need to be explored further as a means of acquiring an asset base. In Kenya, merry-go-rounds appear to be an effective means of obtaining capital and their uses beyond Kenya through south-south learning could be explored.

\section{Support through food and cash transfer projects.}

First it is necessary to identify when a focus on cash rather than food transfers is more appropriate. If food supplementation is a preferred option, findings from the study show that it:

- Needs to be better targeted: Often BMI is used as a key indicator of whether someone should receive food supplementation. While this is an important indicator, findings from the study suggest that perhaps some further, more focused, and contextspecific indicators need to be identified. These could include, for instance, the household size, number of income earners, kind of employment, and whether they have a farm/garden. Those who do have a farm/ garden in Zambia, for instance, appear to be relatively better off and may not need food supplementation as much as those who do not have such assets.

- Needs to be better time-defined: It is important to define at the start the timeframe during which each person will obtain the food supplementation; the study found that people lacked this information; if they had known, they may have been able to plan better their future livelihood strategies for once the food supplementation ceased.

- Should be viewed as an addition to an existing livelihood, not a replacement: Organizations handing out food supplements should encourage those who are healthy to continue engaging in livelihood activities, to continue gardening or farming and not rely solely on the food supplementation. As findings show, food supplementation is unpredictable and usually of short duration, hence a longer term perspective would assist with future livelihood security. Food distribution organizations could also link recipients with organizations supporting longer term livelihood planning including urban farming and credit-providing organizations.
If cash transfers are chosen, findings from the study show that:

- The most appropriate forms given a specific context and situation need to be identified: Cash transfer programs can take many forms. Different models need to be reviewed and findings from existing programs need to be assessed for their relative weaknesses and strengths. Thus, for instance, for those who are very sick, food may be better than cash, but once people on ART start getting well again, perhaps cash transfers may be more appropriate from a longer livelihood perspective. $\mathcal{X}$

July 2008

${ }^{1} \mathrm{~A}$ consensus has been reached in which three distinct variables are seen as being central to the attainment of food security: food availability_sufficient quantities of appropriate, necessary types of food from domestic production, commercial imports, or donors are consistently available to individuals or are in reasonable proximity to them; food access - individuals have adequate incomes or other resources to purchase or barter to obtain levels of appropriate foods needed to maintain consumption of an adequate diet and nutritional level; and food utilization-food is properly used: existence of proper food processing and storage practices, adequate knowledge and application of nutrition and child care, and adequate health and sanitation services.

${ }^{2}$ For a detailed reviewed of the literature refer to Edstrom and Samuels 2007.

${ }^{3}$ The number of meals per day was not asked in the Kenyan quantitative survey.

${ }^{4} \mathrm{Ks} 5,000=$ USD 1. 


\section{References}

Edstrom, J. and F. Samuels. 2007. "HIV, nutrition, food and livelihoods in sub-Saharan Africa: Evidence, debates and reflections for guidance," report prepared for DFID.

FANTA. 2007. Household Food Insecurity Access Scale (HFIAS) for Measurement of Food Access: Indicator Guide VERSION 3.

NASCOP 2005. National AIDS and STI Control Programme, Ministry of Health, Kenya. AIDS in Kenya, $7^{\text {th }} \mathrm{ed}$.

Samuels, F., M. Drinkwater, and M. McEwan. 2006. "Understanding HIV/AIDS and livelihoods: The contribution of longitudinal data and cluster analysis," ODI Briefing Paper.

UNAIDS. 2007. AIDS epidemic update : December 2007.

UNDP. 2003. Human development indicators 2003. (http://www.undp.org/hdr2003/indicator/index.html)

WHO. 2008. “Towards Universal Access: Scaling up priority HIV/AIDS interventions in the health sector Progress Report 2008."
Principal investigators include: Fiona Samuels, Overseas Development Institute, London, UK; Naomi Rutenberg, Horizons/ Population Council, Washington DC, USA; Joseph Simbaya, Institute of Economic and Social Research, University of Zambia, Lusaka, Zambia; Jerry Okal, Nicodemus Kisengese, and Stanley Luchters, International Centre for Reproductive Health, Mombasa, Kenya; and Susan Kaai and Scott Geibel, Horizons/ Population Council, Nairobi, Kenya.

Suggested citation: Samuels, Fiona, Naomi Rutenberg, Joseph Simbaya, Jerry Okal, Nicodemus Kisengese, Stanley Luchters, Susan Kaai, and Scott Geibel. 2008. "Food on the table: The role of livelihood strategies in maintaining nutritional status among ART patients in Kenya and Zambia," Horizons Research Summary. Washington, DC: Population Council.

\section{Hqrizons}

Population Council/Horizons

Communications Unit

4301 Connecticut Avenue, NW

Suite 280

Washington, DC 20008
This research summary is made possible by the generous support of the American people through the United States Agency for International Development (USAID) and the President's Emergency Plan for AIDS Relief under the terms of HRN-A-00-97-00012-00. The contents are the responsibility of the Horizons Program and do not necessarily reflect the views of USAID or the United States Government. 